\title{
Identification of the Infection Route of a Fusarium Seed Pathogen into Nondormant Bromus tectorum Seeds
}

\author{
JanaLynn Franke, Brad Geary, and Susan E. Meyer
}

First and second authors: Department of Plant and Wildlife Sciences, Brigham Young University, Provo, UT 84602; and third author: U.S. Department of Agriculture Forest Service Rocky Mountain Research Station, Shrub Sciences Laboratory, Provo, UT 84606. Accepted for publication 6 June 2014.

\section{ABSTRACT}

Franke, J., Geary, B., and Meyer, S. E. 2014. Identification of the infection route of a Fusarium seed pathogen into nondormant Bromus tectorum seeds. Phytopathology 104:1306-1313.

The genus Fusarium has a wide host range and causes many different forms of plant disease. These include seed rot and seedling blight diseases of cultivated plants. The diseases caused by Fusarium on wild plants are less well-known. In this study, we examined disease development caused by Fusarium sp. $\mathrm{n}$ on nondormant seeds of the important rangeland weed Bromus tectorum as part of broader studies of the phenomenon of stand failure or "die-off" in this annual grass. We previously isolated an undescribed species in the F. tricinctum species complex from die-off soils and showed that it is pathogenic on seeds. It can cause high mortality of nondormant $B$. tectorum seeds, especially under conditions of water stress, but rarely attacks dormant seeds. In this study, we used scanning electron microscopy (SEM) to investigate the mode of attack used by this pathogen. Nondormant $B$. tectorum seeds (i.e., florets containing caryop- ses) were inoculated with isolate Skull C1 macroconidia. Seeds were then exposed to water stress conditions $(-1.5 \mathrm{MPa})$ for 7 days and then transferred to free water. Time lapse SEM photographs of healthy versus infected seeds revealed that hyphae under water stress conditions grew toward and culminated their attack at the abscission layer of the floret attachment scar. A prominent infection cushion, apparent macroscopically as a white tuft of mycelium at the radicle end of the seed, developed within $48 \mathrm{~h}$ after inoculation. Seeds that lacked an infection cushion completed germination upon transfer to free water, whereas seeds with an infection cushion were almost always killed. In addition, hyphae on seeds that did not initiate germination lacked directional growth and did not develop the infection cushion. This strongly suggests that the fungal attack is triggered by seed exudates released through the floret attachment scar at the initiation of germination. Images of cross sections of infected seeds showed that the fungal hyphae first penetrated the caryposis wall, then entered the embryo, and later ramified throughout the endosperm, completely destroying the seed.
The invasive winter annual grass Bromus tectorum (cheatgrass, downy brome) forms extensive near-monocultures over hundreds of thousands of hectares in semiarid regions of western North America. A common but poorly understood phenomenon in $B$. tectorum stands is the occurrence of stand failure or "die-off" over sometimes large areas. Stand failure in B. tectorum is thought to be caused by soilborne pathogens, possibly related to those that cause similar stand failure in winter cereal crops (1). In a recent study, Fusarium sp. n isolates representing an undescribed species in the Fusarium tricinctum species complex were obtained from killed nondormant (readily germinable) $B$. tectorum seeds that had been planted into die-off soils (26). These Fusarium isolates were found to be highly pathogenic on nonormant B. tectorum seeds, particularly under water-stress conditions, simulating field conditions following early autumn storms. In the pathogenicity test, nondormant seeds were inoculated with Fusarium sp. n macroconidia and kept at $-1.5 \mathrm{MPa}$ for 1 week. The seeds were subsequently exposed to a free-water environment at which point 25 to $83 \%$ of the seeds were killed. Even without the water-stress treatment, mortality as high as $43 \%$ was observed. These results suggested that Fusarium sp. n might be an important causal organism implicated in the die-off phenomenon and prompted further studies of its pathogenesis on B. tectorum seeds.

Corresponding author: J. Franke; E-mail address: janalynn.franke@ gmail.com

* The $\boldsymbol{e}$-Xtra logo stands for "electronic extra" and indicates that Figure 4 appears in color online.

http://dx.doi.org/10.1094/PHYTO-03-14-0077-R

(c) 2014 The American Phytopathological Society
Members of the genus Fusarium are important crop pathogens worldwide and have been the subject of intensive study, particularly those species that impact winter cereal crops (11). Several Fusarium species are reported to cause seed "rot" diseases, often as part of a complex of diseases that affect different stages of the host, such as seeds, seedlings, and the crowns of developing plants (e.g., diseases caused by $F$. graminearum and related species) (29). When seed rot and seedling blight are caused by the same organism, preemergence mortality may be due to pathogen attack either before or after germination. There are apparently few studies on the mode of attack by Fusarium directly on ungerminated seeds. The most extensive work has been with $\mathrm{Fu}$ sarium species that infect maize seed $(5,6,21)$. More recently, work has been done on species pathogenic on the seeds of rootparasitic plants in the context of biological control. Heiko et al. (15) showed that infection by $F$. oxysporum f. sp. orthoceras resulted in the destruction of the germ tube of the seed and reduced the number of parasitic attachments of Orobanche cumana to its host plant (sunflower). In a more recent study (30), a $F$. oxysporum isolate from Germany was noted to have the capability to reduce $O$. ramosa seed germination by $40 \%$. In a more specialized study regarding the mode of infection for F. nygamai into Striga hermonthica seeds, Sauerborn et al. (34) showed that this pathogen penetrated the seed coat along the cell walls, thereby requiring less energy, and that penetration culminated in the disintegration of the embryo and endosperm.

Baughman and Meyer (1) determined that dormant (not readily germinable) B. tectorum seeds occurred at similar densities in the persistent seed banks of die-off and adjacent non-die-off soils. This suggested that the pathogen responsible for seed death and stand failure only impacted nondormant seeds in the process of 
initiating germination and had little or no effect on dormant seeds. Most studies of the interactions between seeds and their pathogens in the "spermosphere" have involved crop species whose seeds are nondormant at planting, so that the impact of dormancy status on pathogenesis has not been considered (31). Studies of losses to potentially pathogen-caused decay in weed seed banks have also not explicitly considered dormancy status, even though seed dormancy in weeds of arable lands is common (10). The relationship between seed dormancy and pathogen-caused mortality has recently received theoretical consideration, but there are few empirical studies available to test model predictions (4).

Although we have isolated Fusarium sp. n strains from die-off soils and demonstrated their pathogenicity on B. tectorum seeds, the actual mechanism used by the fungus to infect and kill rapidly germinating, nondormant $B$. tectorum seeds is poorly understood. Therefore, the objective of this study was to visually examine the mode of attack that is implemented by this pathogen to cause mortality of nondormant $B$. tectorum seeds and to gain insight into why it may be less able to attack dormant seeds.

\section{MATERIALS AND METHODS}

Genetic identification. The Fusarium sp. n isolate Skull C1 used in the current study was obtained from the strain collection used by Meyer et al. (26) in the pathogenicity test previously described. Amplification of a portion of the TEF (translation elongation factor) gene was conducted using primers ef1 (forward primer; $5^{\prime}$-ATGGGTAAGGA(A/G)GACAAGAC-3') and ef2 (reverse primer; 5'-GGA(G/A)GTACCAGT(G/C)ATCATGTT-3') (9). Sequencing results were used in a BLAST search of the FUSARIUM-ID (9) and NCBI GenBank databases.

Inoculum production, seed inoculation, and incubation. Skull C1 was cultured onto SNA (Spezieller Nahrstoffaremer agar) lined with one sterile filter paper and grown for 2 to 3 weeks to induce sporulation (22). Once macroconidia were observed, spores were suspended in sterile $\mathrm{ddH}_{2} \mathrm{O}$ (double deionized water) by pipetting $10 \mathrm{ml}$ of $\mathrm{ddH}_{2} \mathrm{O}$ into the petri dish and gently knocking the spores off of the mycelium with the back of a sterile spatula. Spore concentration was determined with a hemacytometer and diluted to 250,000 spores $\mathrm{ml}^{-1}$. Nondormant B. tectorum seeds (Brigham Young University Farm, Spanish Fork, UT; 2011) were immersed in the spore suspension and shaken for $1 \mathrm{~min}$; excess inoculum was then discarded. Inoculated seeds were placed in a sterile petri dish lined with a PEG-8000 (polyethylene glycol)-soaked blue blotter (Anchor Paper Company, St. Paul, $\mathrm{MN})$. The PEG concentration was calculated to create a water potential of $-1.5 \mathrm{MPa}$ (27) and was checked with the Aqualab dew point water activity meter 4TE (Decagon, Pullman, WA). Seeds were incubated at $25^{\circ} \mathrm{C}$ in the PEG solution for 7 days and then transferred to free water and incubated at $25^{\circ} \mathrm{C}$ for up to 14 additional days.

Sample selection, preparation, and viewing. Inoculated seeds were randomly sampled at 2, 24, 48, 72, and $96 \mathrm{~h}$ after inoculation. Selected samples were then fixed by gently placing

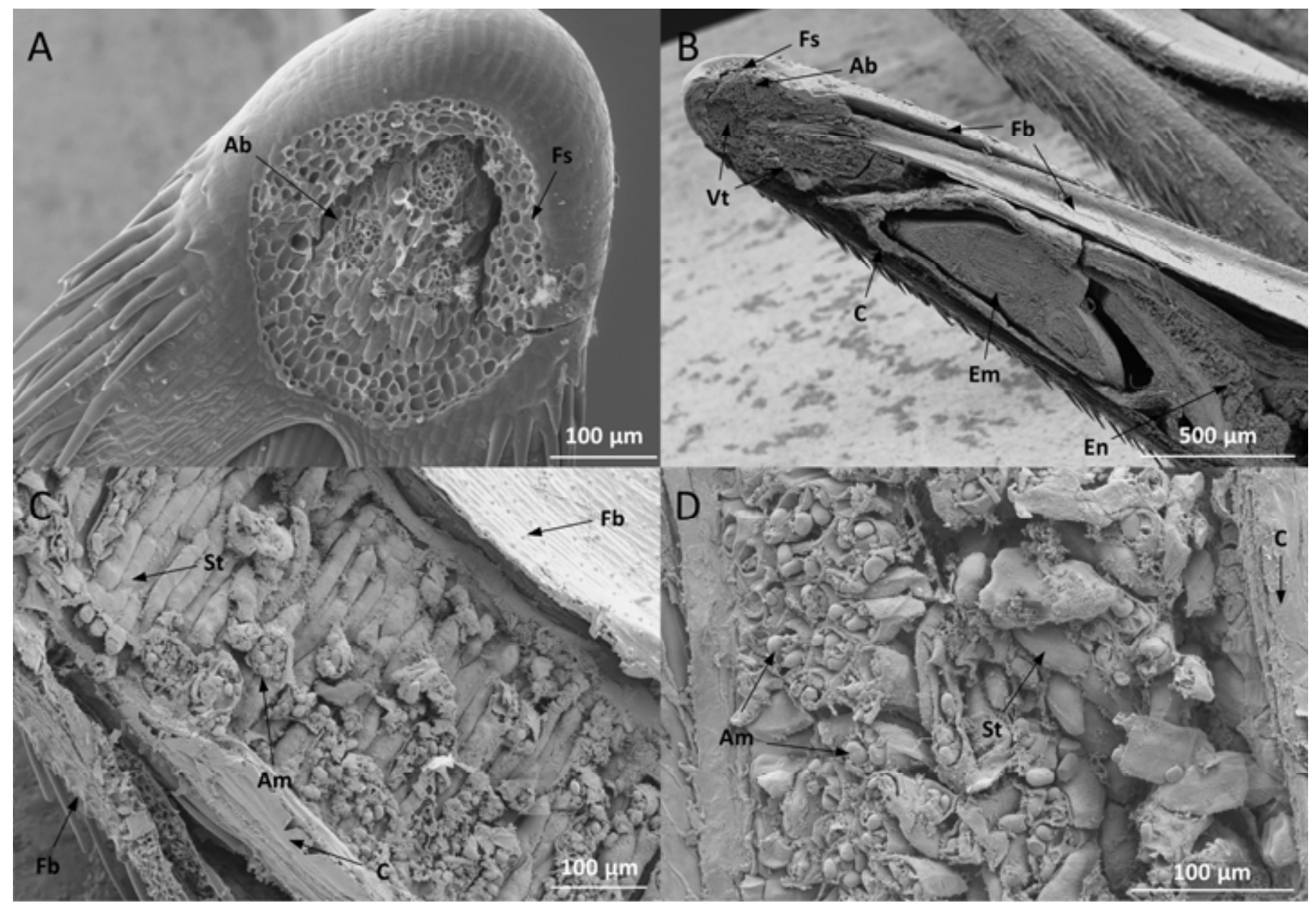

Fig. 1. Scanning electron microscopic images of uninoculated Bromus tectorum seeds. A, Abscission layer (Ab) of the floret attachment scar (Fs). B, Vertical cross section showing the unimbibed caryopsis surrounded by the floret bracts $(\mathrm{Fb})$. The vascular tissue $(\mathrm{Vt})$ begins at the abscission layer $(\mathrm{Ab})$ of the attachment scar (Fs) and ends at the caryopsis wall. Inside are the embryo (Em) and the endosperm (En). C, A close up of the cross section of the unimbibed endosperm with amyloplast $(\mathrm{Am})$ filled starch cells $(\mathrm{St})$. It is protected by the floret bracts $(\mathrm{Fb})$ on the outside and the caryopsis wall $(\mathrm{C})$ on the immediate exterior. D, A close up of imbibed B. tectorum endosperm with starch cells ( $\mathrm{St}$ ) which have begun to digest the amyloplasts $(\mathrm{Am})$. The endosperm is protected by the caryopsis wall (C). 
samples into a $2 \%$ gluteraldehyde mixture for $48 \mathrm{~h}$. The fixed samples were placed into a sodium cacodylate working buffer at a $\mathrm{pH}$ of 7.2 to 7.4 to wash the samples. The buffer solution was replaced five times at 15-min intervals using the same buffer. Ethanol dehydration steps were then used with ethanol concentrations of 30, 50, 75 (five times, each for $15 \mathrm{~min}$ ), 90, and $100 \%$ (five times, each for $30 \mathrm{~min}$ ). Finally, dehydrated samples were dried in a critical-point dryer (Tousimis Autosamdri 931.GL, Rockville, MD) to ensure sample preservation by first replacing $100 \%$ ethanol with liquid carbon dioxide and then carbon dioxide gas.

Each sample was mounted to a metal stub using epoxy. Samples were then coated with gold palladium after drying for $24 \mathrm{~h}$. Coated samples were viewed using the FEI XL30 ESEM FEG and the FEI Helios Nanolab 600 electron microscope (FEI, Hillsboro, OR) at a voltage of $5.0 \mathrm{Kv}$.

Vertical cross-section SEM sample preparation and viewing. Cross-section samples were selected from uninfected and severely infected seeds. The uninfected samples were randomly selected from a group of uninoculated nondormant seeds and were photographed both unimbibed and after imbibition. The severely infected samples were visually selected from a dish of nondormant seeds that had been imbibed and inoculated 14 days prior ( 7 days in PEG followed by 7 days in free water). The severely infected samples were chosen based on the appearance of a white tuft at the radicle end of the seed. This ensured that the location of the fungal attack could be visualized within the seed.

Selected samples were fixed and dehydrated using the previously stated protocol for dehydration through the $75 \%$ ethanol solution. Samples were removed from the $75 \%$ ethanol solution and slowly submerged in liquid nitrogen with tweezers, and held down until the bubbling had ceased. The sample was removed from liquid nitrogen and immediately fractured with a frozen razor blade. The fractured sample was immediately placed back into the $75 \%$ ethanol solution to continue dehydration steps. Seed preservation, mounting, coating, and viewing were completed following the previously stated protocol.

\section{RESULTS}

Sequencing results. A nucleotide BLAST query of NCBI GenBank revealed that the TEF region of the Skull $\mathrm{C} 1$ isolate was a $100 \%$ match to accession JX397848, which was obtained from BBA71608 from corn in Serbia. The sequence from this strain was deposited as Fusarium cf. reticulatum, i.e., as similar but not identical to $F$. reticulatum, a member of the $F$. tricinctum species complex. In the associated publication (32), the authors present a phylogenetic tree based on maximum likelihood analysis that includes BBA71608 along with 60 other strains belonging to $F$. tricinctum and other species within the complex. This tree shows that strain BBA71608 falls clearly within the $F$. tricinctum species complex but that it is not identical to any known species. This indicates that the taxon represented by Skull $\mathrm{C} 1$ is an undescribed species within the $F$. tricinctum species complex.

B. tectorum seed anatomy. In B. tectorum, as in most grasses, the dispersal unit is comprised of floret bracts (lemma, palea) that enclose a one-seeded fruit (caryopsis) in which the fruit wall (pericarp) and seed coat (testa) are fused into a single multilayered structure, the caryopsis wall (25; Fig. 1A). Within the caryopsis are the embryo and the endosperm. The attachment scar is located at the embryo end of the floret, near the point of radicle emergence. It represents the vascular tissue through which the

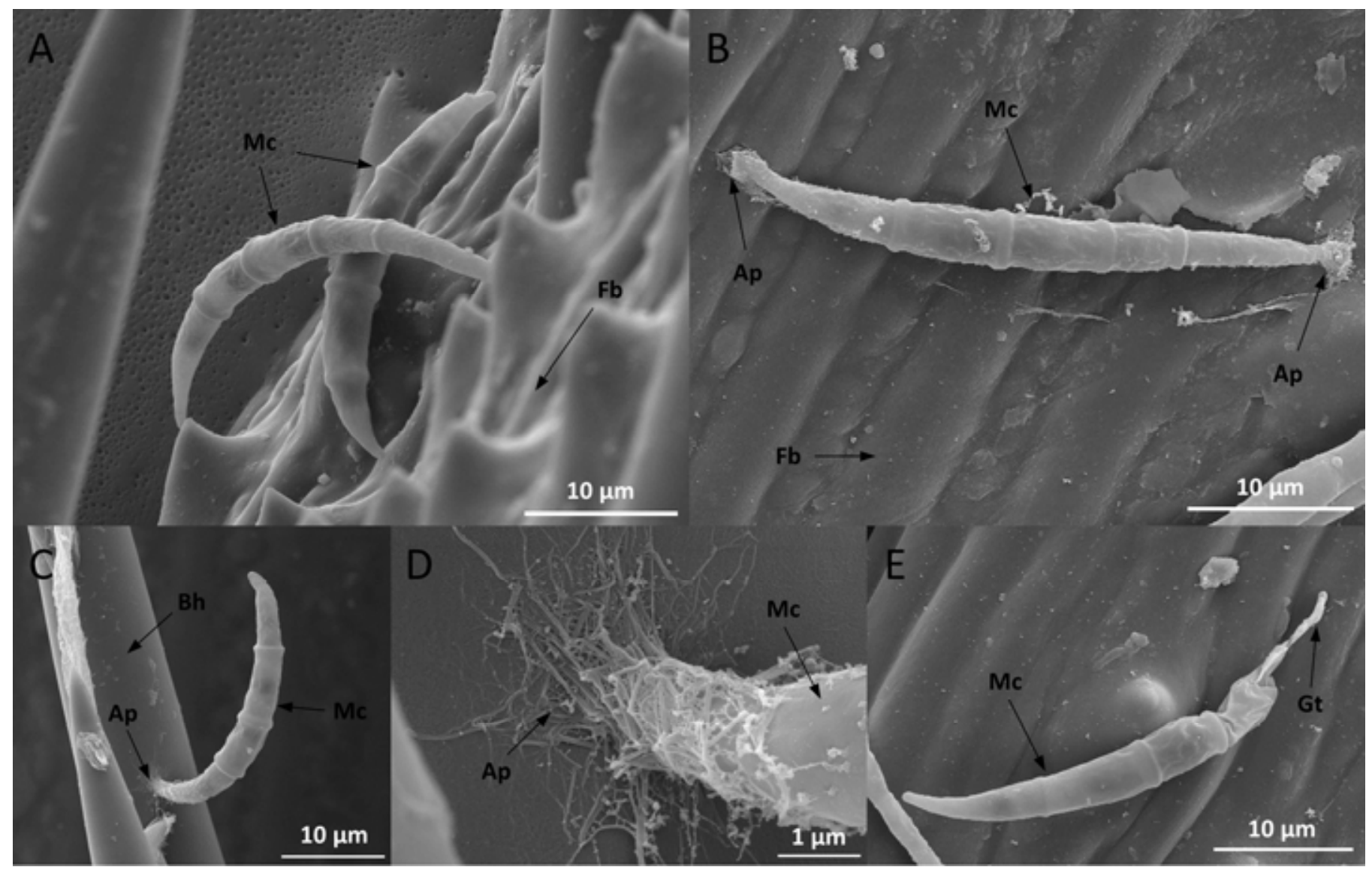

Fig. 2. Scanning electron microscopic images of Skull C1 macroconidia on imbibed Bromus tectorum seeds. A, Macroconidia (Mc) on the floret bracts (Fb) of the seed immediately after inoculation. B, Macroconidial development of an adhesion pad (Ap) on the floret bract (Fb) $2 \mathrm{~h}$ after inoculation. C, Macroconidial development of an adhesion pad (Ap) on bract hair (Bh) $2 \mathrm{~h}$ after inoculation. D, A close up of macroconidial adhesion pad (Ap) as shown in C. E, Macroconidial (Mc) development of a germ tube (Gt) on the surface of the seed $2 \mathrm{~h}$ after inoculation. 
seed was provisioned by the maternal plant. The attachment scar remains after dispersal as a porous, highly vascularized area that represents a direct pathway toward the now-mature caryopsis (Fig. 1B), beginning at the abscission layer and ending at the exterior of the caryopsis wall. Seeds in our research were initially not imbibed; therefore, the endosperm had not begun digestion (Fig. 1C). However, once a nondormant seed becomes imbibed, the seed germination process is initiated. This begins with the digestion of starch cells within the endosperm (Fig. 1D) and presumably results in the diffusion of products of endosperm digestion through the weakening zone of radicle emergence in the caryopsis wall and then through the porous abscission layer.

Fusarium infection process on nondormant $B$. tectorum seeds. Nondormant $B$. tectorum seeds were inoculated with Skull C1 macroconidia and allowed to imbibe while under water stress as described earlier (Fig. 2A). The macroconidia developed adhesion pads only $2 \mathrm{~h}$ after contact with the surface of the floret bracts (Fig. 2B to D). Some macroconidia did not produce adhesion pads but instead immediately produced germ tubes (Fig. 2E).
Within $24 \mathrm{~h}$, the majority of the macroconidia had germinated and begun to focus their hyphal growth toward the abscission layer of the floret attachment scar (Fig. 3A and B). Within $48 \mathrm{~h}$, the hyphae grew preferentially toward and culminated at the abscission layer regardless of macroconidial germination location. The hyphae prepared for penetration down the vascular tissue of the floret attachment scar by developing a large infection cushion (Fig. 3C). Little additional hyphal growth occurred between 48 and $96 \mathrm{~h}$ in PEG (Fig. 3D). During this time, growth was temporarily halted until the water potential was increased by transferring the seeds to free water on day 7 (Fig. 4A), at which point mycelial proliferation recommenced (Fig. 4B). Occasionally a $B$. tectorum seed was able to germinate quickly enough to outgrow the infection cushion (Fig. 5A). On even rarer occasions, a viable seed was apparently still functionally dormant and failed to initiate germination. This resulted in wandering mycelial growth on the surface of the floret bracts in place of a welldeveloped infection cushion at the floret attachment scar, and was similar to the mycelial growth observed on dormant seeds in earlier experiments (Fig. 5B).

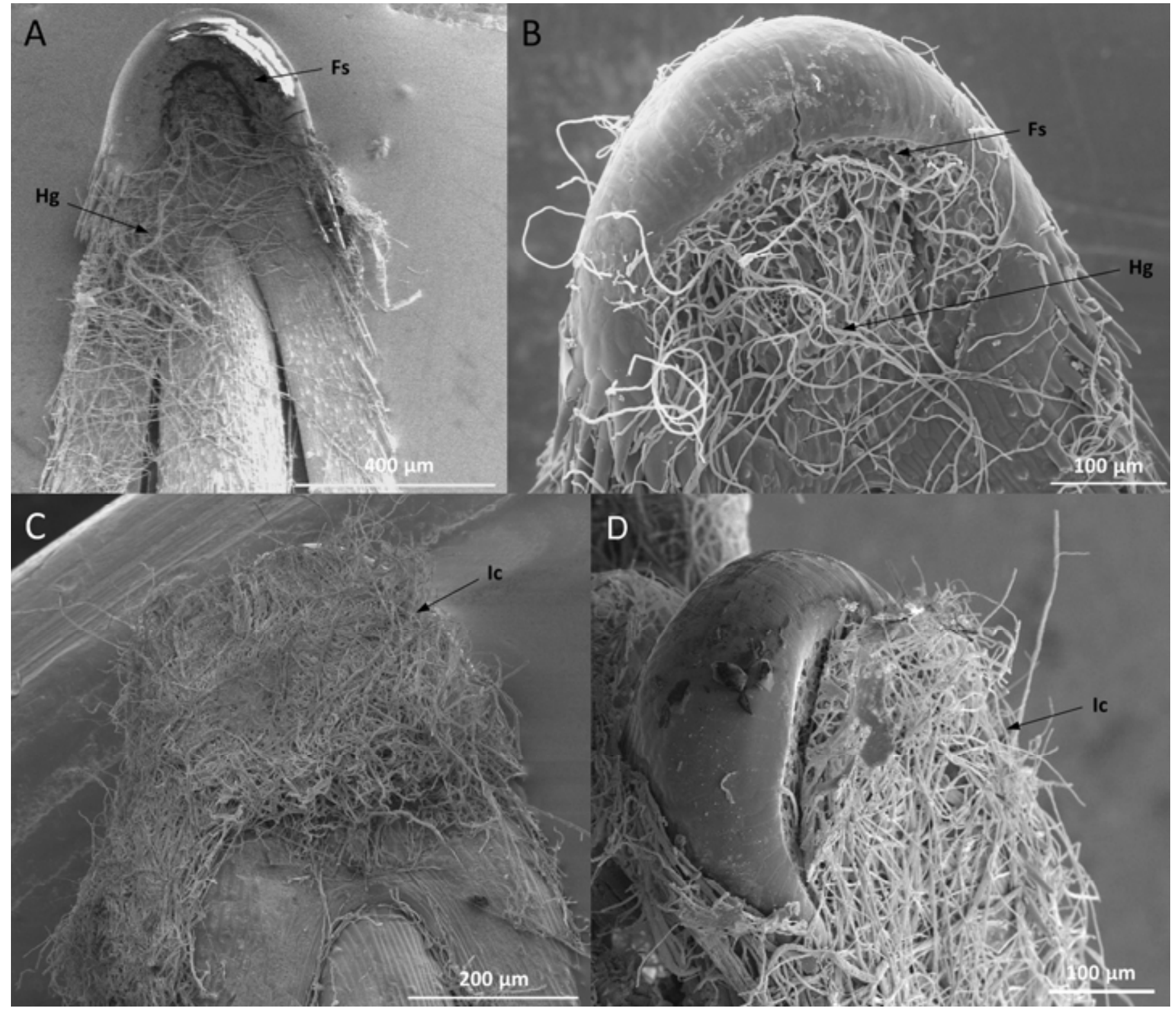

Fig. 3. Scanning electron microscopic time-lapse images of Skull $\mathrm{C} 1$ hyphal growth on imbibed Bromus tectorum seeds. A, Hyphal growth (Hg) towards the floret attachment scar (Fs) $24 \mathrm{~h}$ after inoculation. B, Close-up of hyphal growth $(\mathrm{Hg})$ at floret attachment scar (Fs) $24 \mathrm{~h}$ after inoculation. C, An infection cushion (Ic) is developed at the abscission layer of the floret attachment scar $48 \mathrm{~h}$ after inoculation. D, Infection cushion (Ic) $96 \mathrm{~h}$ after inoculation. 
Vertical cross section of infected seed. Because the infection of the embryo takes place within the floret bracts, a vertical cross section was necessary to identify the location of the mycelial attack (Fig. 6). Fourteen days after macroconidial inoculation (7 days after transfer to free water), hyphae had successfully colonized the vascular tissue of the seed attachment scar (Fig. 7A). During the 7 days in water, penetration hyphae successfully breached the caryopsis wall and came in contact with the nutrientrich embryo. Colonization began in the intercellular region and eventually spread to intracellular growth (Fig. 7B and C). Once colonization in the embryo had occurred, hyphae grew into the endosperm where they began intercellular growth (Fig. 7D). The end result was the complete destruction of the nondormant B. tectorum seed.

\section{DISCUSSION}

The regulation of Fusarium pathogenesis on seeds in an artificial inoculation experiment may be quite different from the process as it occurs in soil. In semiarid ecosystems, soils are rarely at saturation, and nutrients available to microorganisms are sporadically available at best, resulting in nutrient competition. This can in turn result in the suppression of pathogen spore germination, a phenomenon known as fungistasis $(8,23)$. Fungistasis may be overcome by an increase in nutrient status, which could be provided by a change in the status of organic matter in the soil (3) or directly by exudates from germinating seeds (31). In the experiment described here, Fusarium spores were immediately exposed to an environment conducive to germination, either because of an absence of competing soil microorganisms or possibly because of the presence of seed exudates. It is not known whether the spores in this study are capable of germination in the absence of an exogenous nutrient source, or whether the imbibing seeds provided this nutrient source. In either case, spore attachment and germination occurred essentially simultaneously within $24 \mathrm{~h}$ of inoculation.

In previous studies with plant-pathogenic fungi such as Cochliobolus heterostrophus, conidia were capable of forming a firm

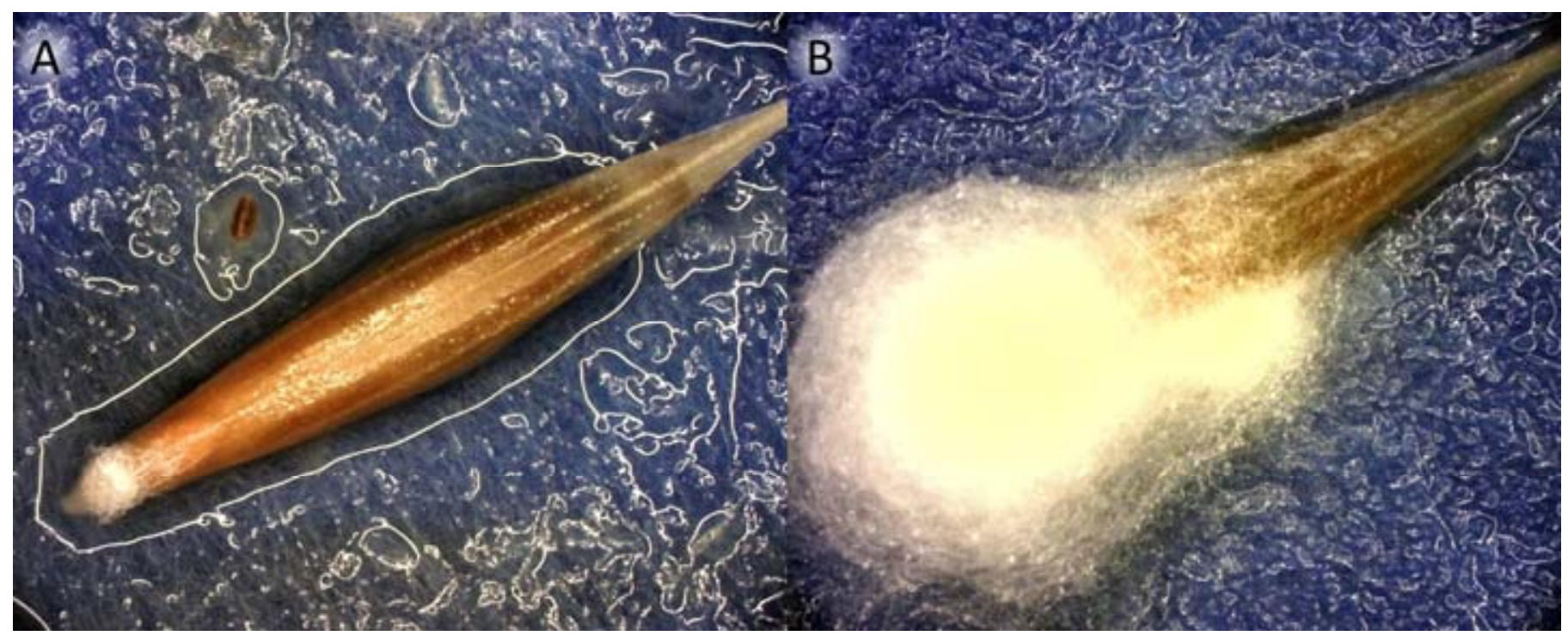

Fig. 4. Images taken of infected seeds (florets). A, Infected Bromus tectorum seed in polyethylene glycol (PEG) 7 days after Skull C1 macroconidial inoculation with a well-developed infection cushion. B, Well-colonized B. tectorum seed in free water 21 days (7 days in PEG and 14 days in free water) after macroconidial inoculation.

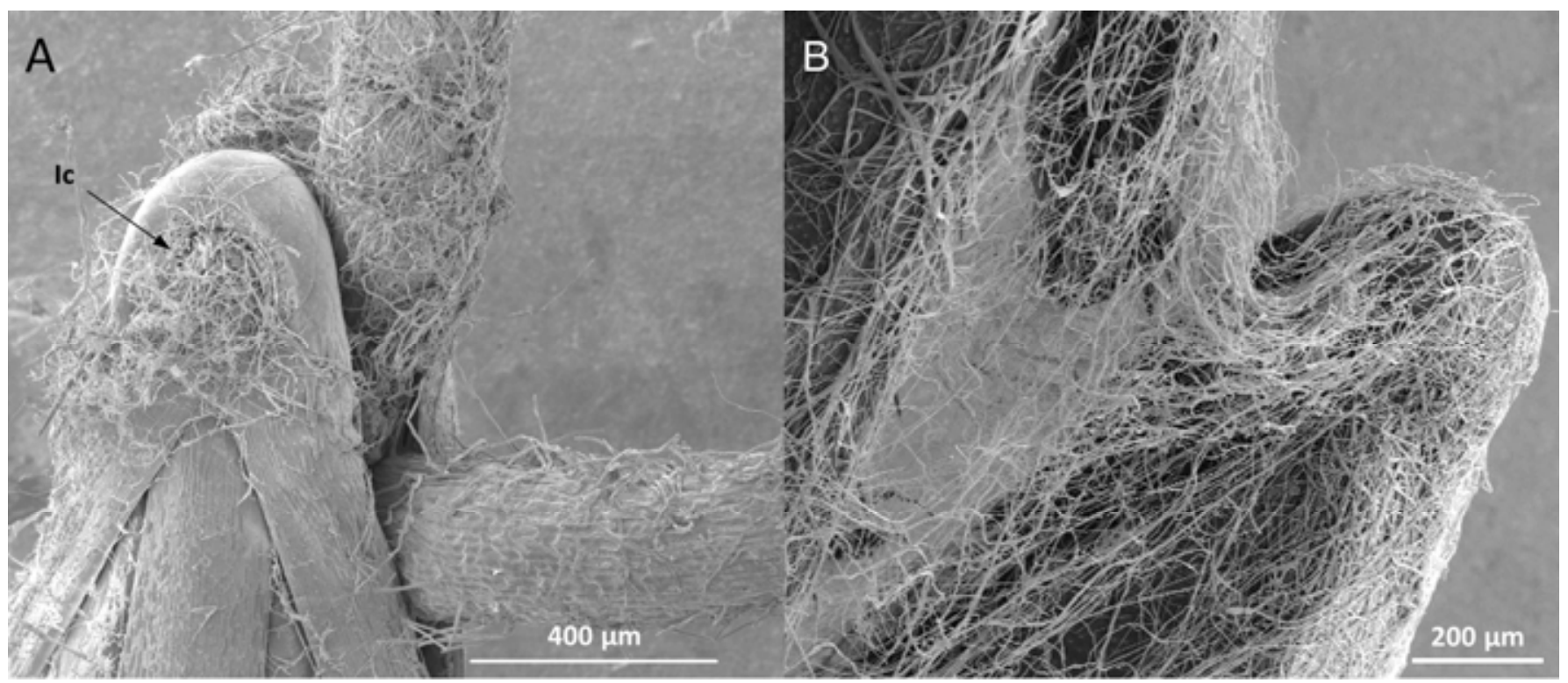

Fig. 5. Scanning electron microscopic images of Skull C1-inoculated Bromus tectorum seeds that escaped infection. A, A weak infection cushion (Ic) on a Bromus tectorum floret 7 days after inoculation, allowing seedling growth. B, Hyphal growth on an inoculated B. tectorum seed that failed to germinate. 
attachment to plant and artificial surfaces within 60 min after inoculation (2). According to Jones and Epstein (17), many plantpathogenic fungi depend on spore attachment as the first step in host infection. Their results showed that mutants incapable of attaching to the host had a dramatic decrease in virulence on nonwounded host tissue (fruit). The extracellular matrix material produced prior to germ tube production proved to be the key to infection and was not dependent on nutrient availability. In this study system, this initial step most likely happens in the field in the first wetting event after spore dissemination.

As mentioned earlier, there is evidence that the Fusarium sp. $\mathrm{n}$ strains implicated in B. tectorum die-offs only effectively attack germinating (nondormant) seeds (1). Evidence gathered from the vertical cross-sectional view of an uninoculated nondormant $B$. tectorum seed suggests that the vascular tissue of the floret attachment scar could be the exit route for exudates released by the germinating seed. This would result in the directional growth toward the abscission layer of the floret attachment scar as exhibited by the Skull C1 isolate in this study. Spores were able to germinate on seeds that did not initiate germination, but hyphal growth meandered with no obvious direction. The directional pattern of response to an apparent nutrient gradient emanating from the radicle end of a germinating seed permitted the pathogen to target the most vulnerable point on the seed and to rapidly complete penetration before radicle protrusion could occur following transfer to free water.
The development of hyphae dramatically increases fungal nutrient acquisition. Numerous studies have examined the mechanisms behind hyphal growth. Riquelme et al. (33) showed that in Neurospora crassa the spitzen korper position located on the tip of hyphae directly affects the direction and morphology of hyphal growth. Their results showed directional fungal growth and the hyphal ability to adaptively change direction. Grow (12) discussed the different mechanisms used by fungi for directional orientation, such as thigmotropism (which was not apparent in this study). A second mechanism is directional growth in response to chemical gradients. In the present study, it appears that the recognition of a gradient of seed exudates emanating from the floret attachment scar allowed hyphae to sense the most direct path to the source of nutrients. This resulted in a conspicuous white infection cushion at the abscission layer of the floret attachment scar.

There was no evidence suggesting that Skull C1 used advanced morphological structures to penetrate the exterior of the floret bracts or the caryopsis wall. Studies have shown that some fungal species have forgone penetration structure development and completely bypassed the plant cuticle by taking advantage of features of plant or seed anatomy to infect the host (e.g., through the stomates; 19). According to Mendgen et al. (24), some Fusarium species enter their host with little cell differentiation or, in other words, a very underdeveloped appressorium. These $\mathrm{Fu}$ sarium species use a method in which they produce a net-like mat

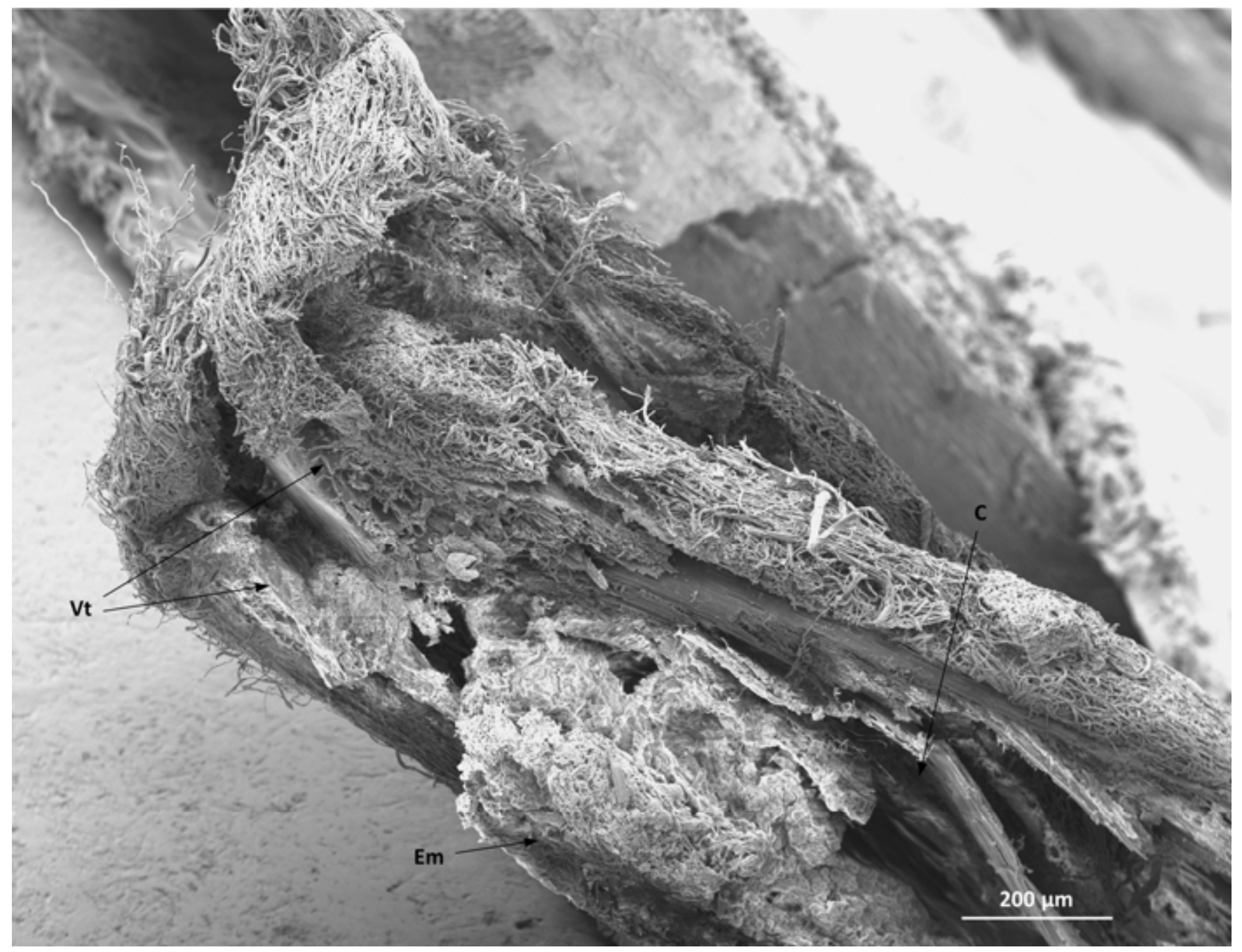

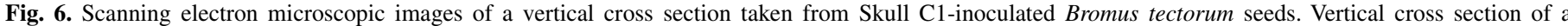

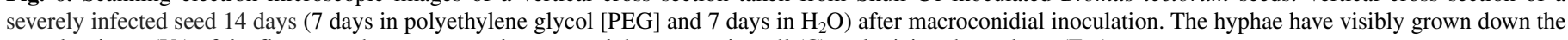
vascular tissue $(\mathrm{Vt})$ of the floret attachment scar and penetrated the caryopsis wall $(\mathrm{C})$, colonizing the embryo (Em). 
of mycelium where the penetration hyphae are produced. This method is very similar to the pattern observed in the present study. By taking advantage of the porous floret attachment scar and the weakening caryopsis wall at the point of radicle emergence, Skull C1 was able to penetrate host tissues and cause seed death without appressorial development.

According to our results, water stress at $-1.5 \mathrm{MPa}$ prevented seeds from completing germination while fungal growth could still occur, a result similar to that observed with Pyrenophora semeniperda, another B. tectorum seed pathogen (7). However, we observed that for Skull C1 there was a growth lag between $48 \mathrm{~h}$ in PEG and exposure to free water. It appears that this Fusarium species can germinate, grow directionally, and produce an infection cushion at reduced water potential. However, the actual penetration of the caryopsis wall, and subsequent access to the abundant resources within the seed, did not take place until after transfer to free water. Seeds are also allowed to complete germination normally once exposed to free water. However, by this time, Skull $\mathrm{C} 1$ had already penetrated the floret bracts and was ready to penetrate the caryopsis wall.

Money (28) showed that hyphae require a substantial amount of turgor pressure to penetrate solid media. This ultimately is caused by the inability of hyphae to generate enough pressure inside while the exterior pressure is so low. According to Howard et al. (16), penetration of rice by Magnaporthe grisea was significantly reduced after an incubation period of $48 \mathrm{~h}$ in PEG. Mechanical penetration occurred after sufficient turgor pressure was established. In contrast, Harold et al. (14) showed that exposure to low turgor pressure had little effect on hyphal morphogenesis and growth while exposed to water stress. Kaminskyj et al. (18) first noted that hyphal extension and diameter increased when sub- jected to water stress. This was reaffirmed by Money (28). Our research agrees with these previous studies in that Skull C1 growth recommenced after exposure to free water, suggesting that free water is crucial to the production of the turgor pressure required for penetration of the caryopsis wall.

Other confounding variables may decrease hyphal penetration of the caryopsis wall or seed coat. Polyphenolic and phenolic compounds in seed coats and their interactions with pathogens have been studied extensively. Results suggest that hyphae may grow substantially on seed surfaces lower in polyphenolic compounds before penetrating polyphenolic-rich surfaces (such as the seed coat), delaying penetration $(13,20)$. Because such a clear relationship exists in our study between water potential and the growth potential of the hyphae, it may be argued that polyphenolic and phenolic compounds probably played a minor role in protecting the seeds from attack.

This study has demonstrated that Fusarium sp. n pathogenesis on nondormant B. tectorum seeds is focused on the porous tissue of the floret attachment scar, close to the point of potential radicle emergence. This represents the most vulnerable location for pathogen attack on a rapidly germinating seed. A nutrient gradient produced by seed exudates apparently directs hyphal growth toward this attachment scar, where an infection cushion is produced even at water potentials that suppress seed germination. Upon subsequent transfer to free water, the fungus is able to quickly breach the caryopsis wall. This results in rapid colonization of the embryo, seed death, and a major increase in pathogen mycelial production. Knowledge of this mechanism of pathogenesis will enable us to determine how the pathogen operates to cause seed mortality in the field, and will help to clarify its role in the B. tectorum die-off phenomenon.

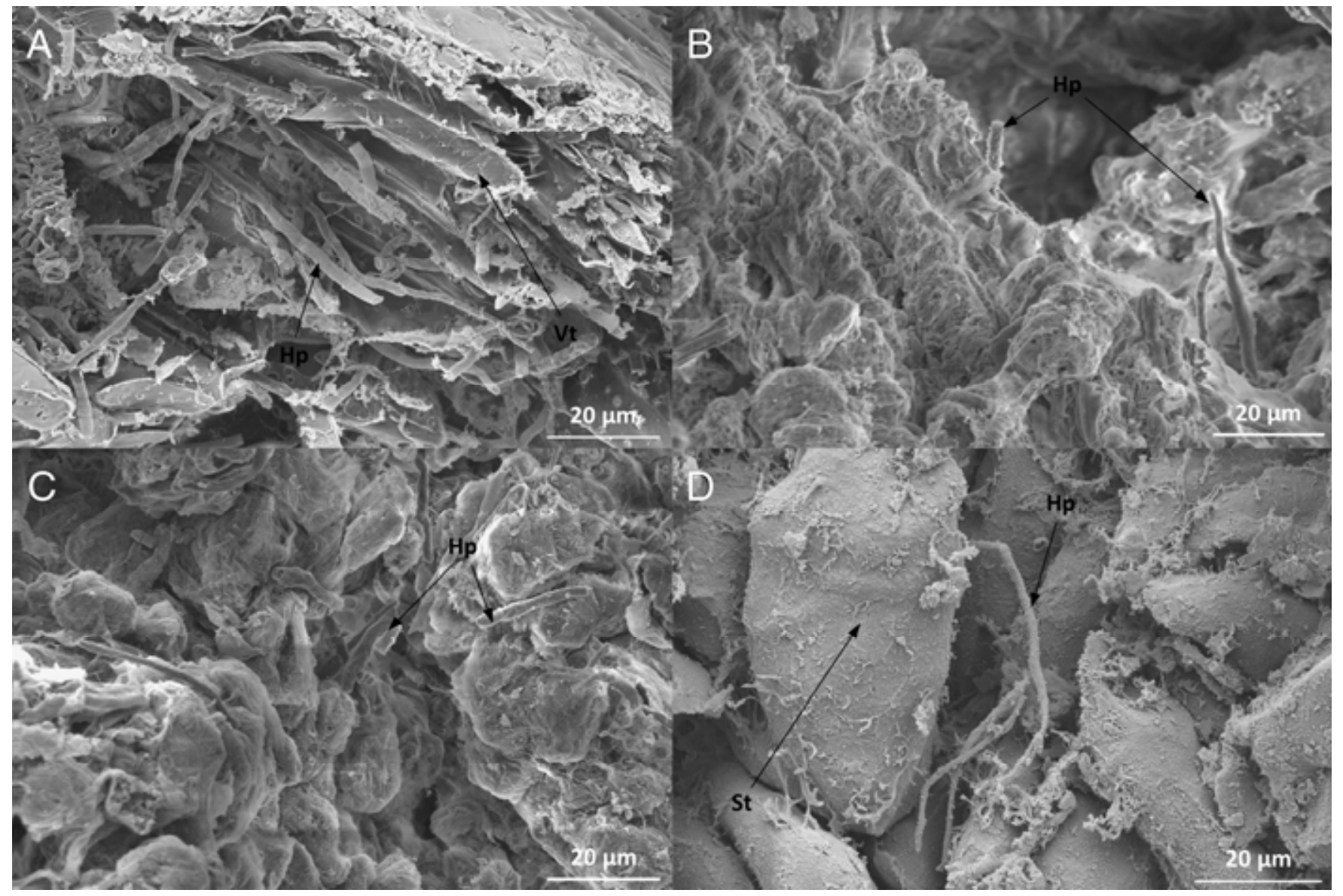

Fig. 7. Scanning electron microscopic images of close-ups of the vertical cross section shown in Figure 6. A, Hyphae (Hp) have grown down and colonized the vascular tissue $(\mathrm{Vt})$ of the floret attachment scar. B and $\mathbf{C}$, Hyphae $(\mathrm{Hp})$ colonizing the embryo. D, Hyphae (Hp) growing in the intercellular region of the endosperm starch cells (St). 


\section{ACKNOWLEDGMENTS}

This research was funded in part by a grant from the USDI Bureau of Land Management Idaho State Office in support of the Integrated Cheatgrass Die-Off Project. We thank H. Finch-Boekweg and M. Standings for microscope assistance in obtaining the images for this paper and S. Sink and K. O'Donnell (NCAUR, ARS, USDA, Peoria, IL) for assistance with the molecular phylogenetic identification of Skull C1.

\section{LITERATURE CITED}

1. Baughman, O. W., and Meyer, S. E. 2013. Is Pyrenophora semeniperda the cause of downy brome (Bromus tectorum) die-offs? Invasive Plant Sci. Manag. 6:105-111.

2. Braun, E. J., and Howard, R. J. 1994. Adhesion of Cochliobolus heterostrophus conidia and germlings to leaves and artificial surfaces. Exp. Mycol. 18:211-220.

3. Bonanomi, G., Gaglione, S. A., Incerti, G., and Zonia, A. 2013. Biochemical quality of organic amendments affects soil fungistasis. Appl. Soil Ecol. 72:135-142.

4. Dalling, J. W., Davis, A. S., Schutte, B. J., and Arnold, A. E. 2011. Seed survival in soil: Interacting effects of predation, dormancy and the soil microbial community. J. Ecol. 99:89-95.

5. Duncan, K. E., and Howard, R. J. 2010. Biology of maize kernel infection by Fusarium verticillioides. Mol. Plant-Microbe Interact. 23:6-16.

6. Fandohan, P., Hell, K., Marasas, W. F. O., and Wingfield, M. J. 2003. Infection of maize Fusarium species and contamination with fumonisin in Africa. Afr. J. Biotechnol. 12:570-579.

7. Finch, H., Allen, P. S., and Meyer, S. E. 2013. Environmental factors influencing Pyrenophora semeniperda-caused seed mortality in Bromus tectorum. Seed Sci. Res. 23:57-66.

8. Garbeva, P., Hol, W. H., Termorshuizen, A. J., Kowalchuk, G. A., and De Boer, W. 2011. Fungistasis and general soil biostasis-a new synthesis. Soil Biol. Biochem. 43:469-477.

9. Geiser, D. M., Jimenez-Gasco, M. D. M., Kang, S., Makalowska, I., Veeraraghavan, N., Ward, T. J., Zhang, N., Kuldau, G. A., and O'Donnell, K. 2004. FUSARIUM-ID v. 1.0: A DNA sequence database for identifying Fusarium. Eur. J. Plant Pathol. 110:473-479.

10. Gomez, R., Liebman, M., and Munkvold, G. 2014. Weed seed decay in conventional and diversified cropping systems. Weed Res. 54:13-25.

11. Goswami, R. S., and Kistler, H. C. 2004. Heading for disaster: Fusarium graminearum on cereal crops. Mol. Plant Pathol. 5:515-525.

12. Grow, N. A. R. 1994. Growth and guidance of the fungal hyphae. Microbiology 140:3193-3205.

13. Halloin, J. M. 1983. Deterioration resistance mechanisms in seeds. Phytopathology 73:335-339.

14. Harold, F. M., Harold, R. L., and Money, N. P. 1995. What forces drive cell wall expansion? Can. J. Bot. 73(S1):379-383.

15. Heiko, T., Sauerborn, J., Muller-Stover, D., Ziegler, A., Singh-Bedi, J., and Kroschel, J. 1998. The potential of Fusarium oxysporum f. sp. orthoceras as a biological control agent for Orobanche cumana in sunflower. Biol. Control 1:41-48.

16. Howard, R. J., Ferrari, M. A., Roach, D. H., and Money, N. P. 1991. Penetration of hard substrates by a fungus employing enormous turgor pressures. Microbiology 88:11281-11284.

17. Jones, M. J., and Epstein, L. 1990. Adhesion of macroconidia to the plant surface and virulence of Nectria haematococca. Appl. Environ. Microbiol. 56:3772-3778.

18. Kaminskyj, S. G. W., Garrill, A., and Heath, I. B. 1992. The relation between turgor and tip growth in Saprolegnia ferax: Turgor is necessary, but not sufficient to explain apical extension rates. Exp. Mycol. 16:64-75.

19. Knogge, W. 1996. Fungal infection of plants. Plant Cell 8:1711-1722.

20. Lattanzio, V., Lattanzio, V. M. T., and Cardinali, A. 2006. Role of phenolics in resistance mechanisms of plant against fungal pathogens and insects. Phytochem. Adv. Res. 661:23-67.

21. Lawrence, E. B., Nelson, P. E., and Ayers, J. E. 1981. Histopathology of sweet corn seed and plants infected with Fusarium monliforme and $F$. oxysporum. Phytopathology 71:379-386.

22. Leslie, J. F., and Summerell, B. A. 2006. The Fusarium Laboratory Manual. Blackwell Publishing, Ames, IA.

23. Lockwood, J. L. 1977. Fungistasis in soils. Biol. Rev. 52:1-43.

24. Mendgen, K., Hahn, M., and Deising, H. 1996. Morphogenesis and mechanisms of penetration by plant pathogenic fungi. Annu. Rev. Phytopathol. 34:364-386.

25. Metcalfe, C. R. 1960. Anatomy of the Monocotyledons. I. Gramineae. Clarendon Press, Oxford, UK.

26. Meyer, S. E., Franke, J.-L., Baughman, O., Beckstead, J., and Geary, B. D. 2014. Does Fusarium-caused seed mortality contribute to Bromus tectorum stand failure in the Great Basin? Weed Res. 54:511-519.

27. Michel, B. E. 1983. Evaluation of the water potentials of polyethylene glycol 8000 both in the absence and presence of other solutes. Plant Physiol. 72:66-70.

28. Money, N. P. 1995. Turgor pressure and the mechanics of fungal penetration. Can. J. Bot. 73(Suppl. 1):S96-S102.

29. Moya-Elizando, E. M. 2013. Fusarium crown rot disease: Biology, interactions, management and function as a possible sensor of global climate change. Cien. Inv. Agric. 40:235-252.

30. Muller-Stover, D., Kohlschmid, E., and Sauerborn, J. 2009. A novel strain of Fusarium oxysporum from Germany and its potential for biocontrol of Orobanche ramosa. Weed Res. 2:175-182.

31. Nelson, E. B. 2004. Microbial dynamics and interactions in the spermosphere. Annu. Rev. Phytopathol. 42:271-309.

32. Niessen, L., Gräfenhan, T., and Vogel, R. F. 2012. ATP citrate lyase 1 (acl1) gene-based loop-mediated amplification assay for the detection of the Fusarium tricinctum species complex in pure cultures and in cereal samples. Internat. J. Food Microbiol. 158:171-185.

33. Riquelme, M., Reynaga-Pena, C. G., Gierz, G., and Bartnicki-Garcia, S. 1998. What determines growth direction in fungal hyphae? Fungal Genet. Biol. 24:101-109.

34. Sauerborn, J., Dorr, I., Abbasher, A., Thomas, H., and Kroschel, J. 1996. Electron microscopic analysis of the penetration process of Fusarium nygamai, a hyperparasite of Striga hermonthica. Biol. Control 7:53-59. 